\title{
Multiband light emission and nanoscale chemical analyses of carbonized fumed silica
}

\author{
A. V. Vasin, ${ }^{1,2}$ D. V. Kysil, ${ }^{1}$ L. Lajaunie, ${ }^{3}$ G. Yu. Rudko, ${ }^{1}$ V. S. Lysenko, ${ }^{1}$ S. V. Sevostianov, ${ }^{4}$ \\ V. A. Tertykh, ${ }^{4}$ Yu. P. Piryatinski, ${ }^{5}$ M. Cannas, ${ }^{6}$ L. Vaccaro, ${ }^{6}$ R. Arenal,,${ }^{3,7, a)}$ \\ and A. N. Nazarov ${ }^{1,2, a)}$ \\ ${ }^{1}$ Lashkaryov Institute of Semiconductor Physics, Kyiv, Ukraine \\ ${ }^{2}$ National Technical University of Ukraine "I. Sikorsky KPI", Kyiv, Ukraine \\ ${ }^{3}$ Laboratorio de Microscopías Avanzadas, Instituto de Nanociencia de Aragon, Universidad de Zaragoza, \\ 50018 Zaragoza, Spain \\ ${ }^{4}$ Chuiko Institute of Surface Chemistry, Kyiv, Ukraine \\ ${ }^{5}$ Institute of Physics, Kyiv, Ukraine \\ ${ }^{6}$ Dipartimento di Fisica e Chimica, Universita degli Studi di Palermo, I-90123 Palermo, Italy \\ ${ }^{7}$ ARAID Foundation, 50018 Zaragoza, Spain
}

(Received 3 June 2018; accepted 26 August 2018; published online 14 September 2018)

\begin{abstract}
Fumed silica with a specific area of $295 \mathrm{~m}^{2} / \mathrm{g}$ was carbonized by successive phenyltrimethoxysilane treatments followed by annealing in inert atmosphere up to $650^{\circ} \mathrm{C}$. Emission, excitation, kinetics, and photo-induced bleaching effects were investigated by steady state and time-resolved photoluminescence spectroscopies. The local chemistry was also studied by infrared transmission spectroscopy. Strong ultraviolet and visible photoluminescence was observed in the samples after the chemical treatments/modifications and thermal annealing. It has been shown that ultraviolet photoluminescence in chemically modified fumed silica is associated with phenyl groups, while near ultraviolet and visible emission in annealed samples originated from inorganic pyrolytic carbon precipitates dispersed in the silica host matrix. Two types of emission bands were identified as a function of the annealing temperature: one is in the near UV and the other is in the visible range. Based on the emission/excitation analysis of these two bands, as well as on correlations with the synthesis conditions, a structural-energy concept of light-emitting centers has been proposed. According to this model, the light-emitting centers are associated with carbon clusters that can be bonded or adsorbed on the silica surface. This has been validated by a detailed (S)TEM-electron energy-loss spectroscopy study, confirming the inhomogeneous distribution of nanoscale carbon precipitates at the surface of the silica nanoparticles. These carbon precipitates are mostly amorphous although they possess some degree of graphitization and local order. Finally, the fraction of $\mathrm{sp}^{2}$ carbon in these nanoclusters has been estimated to be close to $80 \%$. Published by AIP Publishing. https://doi.org/10.1063/1.5042671
\end{abstract}

\section{INTRODUCTION}

Luminescent materials in a visible spectra range are of great importance in modern optoelectronics, artificial lighting, and visualization/indication technologies. ${ }^{1}$ The inorganic segment of such materials is mainly occupied by multicomponent ceramics doped by optically active rearearth metals. Limited natural resources and high price of rear-earth metals as well as their undesirable effects on environment and human health stimulate research activity in the development of efficient alternatives. In the last decade, great performances have been achieved in the development of luminescent semiconductor nanoparticles (SNPs). Their applications have been successively implemented, for instance, in bioimaging nanolabels ${ }^{2}$ and multicolour phosphors in the new generation of large screen TVs (QLED TVs). For nanoparticles, the choice of the materials is also restricted by human health safety demands. For instance, the application of nanoparticles (NPs) of $\mathrm{Cd}$ - and $\mathrm{Pb}$-containing

\footnotetext{
${ }^{\text {a) }}$ Authors to whom correspondence should be addressed: arenal@unizar.es, Tel.: +34 976762985 and nazarov@lab15.kiev.ua, Tel.: +380 (44) 525 6177.
}

compounds (i.e., $\mathrm{CdSe}, \mathrm{CdTe}, \mathrm{PbS}$, and $\mathrm{PbSe}$ ), which can be relatively easily synthesized with precisely controlled size and emission spectrum, ${ }^{3}$ is severely limited due to their toxicity. In fact, since 2006, the application of such NP has been banned by European regulations. ${ }^{4}$ Thus, recent R\&D efforts are focusing on In and $\mathrm{Zn}$ based luminescent nanoparticles, ${ }^{5}$ as well as on searching of new effective fluorophores with an optimal combination of different factors including an easy production process, good emission properties, and no risk for human safety. Recently, it has been reported that carbon incorporated nanostructured silica exhibits strong photoluminescence in the near-UV and visible spectral range. ${ }^{6-12}$ It was demonstrated that spectral properties of emission light can be tuned over the visible range as a function of the preparation conditions of such nanostructures. ${ }^{6,12}$ The authors of Refs. 6 and 7 put forward the hypothesis that luminescent centers are associated with carbon species in the form of subnanometer clusters and/or nanoparticles. This hypothesis looks quite realistic in the light of recent advances in the synthesis and science of luminescent carbon nanodots. ${ }^{13,14}$ Nevertheless, other mechanisms, involving optically active bulk/surface defects in amorphous silica are suggested and 
discussed as emission centers. ${ }^{8-11}$ The development of physical mechanisms of light emission in such nanostructured materials needs more detailed investigations. The present work combines optical, structural, and chemical analyses in order to extract a wealth of information on the luminescent properties of carbonized fumed silica and on their chemistry.

\section{EXPERIMENT}

\section{A. Synthesis of the material}

Nanodispersed fumed silica powder with a specific surface area of $295 \mathrm{~m}^{2} / \mathrm{g}$ was used as a nanostructured silica matrix. Before chemical modification, the fumed silica was annealed in air at $600{ }^{\circ} \mathrm{C}$ for $30 \mathrm{~min}$ to remove carbon contamination. Afterwards, it was dispersed in a toluene solution of phenyltrimethoxysilane (PhTMS, $1.73 \mathrm{ml}$ of PhTMS per $10 \mathrm{ml}$ of toluene) at a temperature of $70{ }^{\circ} \mathrm{C}$ for $4 \mathrm{~h}$ in the presence of triethylamine as a catalyst. PhTMS reacted with the silica surface through the reaction of electrophilic substitution of proton in the silanol groups present at the surface. This resulted in the formation of $\equiv \mathrm{Si}-\mathrm{O}-\mathrm{Si} \equiv$ bonds and in the elimination of methanol

$$
\begin{aligned}
& \equiv \mathrm{Si}-\mathrm{OH}+\left(\mathrm{H}_{3} \mathrm{CO}\right)_{3} \mathrm{SiC}_{6} \mathrm{H}_{5} \rightarrow \\
& \equiv \mathrm{Si}-\mathrm{O}-\mathrm{Si}\left(\mathrm{OCH}_{3}\right)_{2} \mathrm{C}_{6} \mathrm{H}_{5}+\mathrm{CH}_{3} \mathrm{OH} .
\end{aligned}
$$

Phenyl containing groups $-\mathrm{Si}\left(\mathrm{OCH}_{3}\right)_{2} \mathrm{C}_{6} \mathrm{H}_{5}$ appeared to be covalently bonded to the silica surface through $\mathrm{Si}-\mathrm{O}-\mathrm{Si}$ bonding bridge. Obtained products, phenylsilicas, were washed out with a dissolvent and dried at $80-100^{\circ} \mathrm{C}$. Afterwards, the samples were annealed in a pure nitrogen flow at atmospheric pressure or in vacuum $\left(10^{-4} \mathrm{~Pa}\right)$ for $30 \mathrm{~min}$ at temperatures of $500,600,650$, and $700^{\circ} \mathrm{C}$, resulting in the pyrolytic destruction of organic and organosilicon surface groups followed by carbon precipitation.

\section{B. Structural and chemical characterization}

Interatomic chemical bonds were studied by Fouriertransform infrared spectroscopy (FTIR) in transmission mode using Nicolet 6700/Nicolet Continuum (Thermo Fisher Scientific) equipped with an IR/VIS-microscope that allows measuring IR-transmission within the $50 \times 50 \mu \mathrm{m}$ selected area of the powder sample without using dispersion in a $\mathrm{KBr}$ pellet.

The X-ray photoelectron spectroscopy (XPS) analyses were carried out using a Kratos Axis Supra spectrometer. The photoelectron spectra were excited by a soft X-ray Al $\mathrm{K} \alpha(1486.6 \mathrm{eV})$ anode at a power of $225 \mathrm{~W}(15 \mathrm{~mA}, 15 \mathrm{kV})$. In order to check the influence of surface contamination, XPS spectra were collected before and after a soft gas cluster ion beam (GCIB) etching (Ar, $10 \mathrm{keV}, 30 \mathrm{~s})$. Calibration of the spectra was done by setting the position of the $\mathrm{C} 1 \mathrm{~s}$ peak at $284.9 \mathrm{eV}$. XPS analysis has been carried out by using the Casa XPS software.

Scanning transmission electron microscopy (STEM) studies, and in particular, spatially resolved electron energyloss spectroscopy (SR-EELS) analyses, were performed by using a FEI Titan Low-Base microscope operated at $80 \mathrm{kV}$ and equipped with a Cs probe corrector, a monochromator, an ultra-bright field emission gun (X-FEG) as electron source, and a Gatan Tridiem ESR 865 EELS spectrometer. STEM imaging was performed by using a high-angle annular dark-field detector (HAADF). During SR-EELS analyses, the energy resolution was $0.9 \mathrm{eV}$ with a dispersion of $0.3 \mathrm{eV} /$ pixel. The convergence and collection angles were 18 and 16 mrad, respectively. STEM-EELS experiments were also performed with the monochromator on. In this case, the energy resolution was $0.3 \mathrm{eV}$ for a dispersion of $0.03 \mathrm{eV} /$ pixel. TEM-EELS experiments were also performed to determine the carbon $\mathrm{sp}^{2}$ ratio by using a FEI Titan Cube microscope operated at $80 \mathrm{kV}$ and equipped with a Cs image corrector and a Gatan Tridiem spectrometer. The probe diameter for EELS acquisition was around $30 \mathrm{~nm}$. Convergence and collection angles were 4.6 and $20 \mathrm{mrad}$, respectively. The energy resolution was $0.6 \mathrm{eV}$ for a dispersion of $0.05 \mathrm{eV} /$ pixel. The complete method to determine the carbon $\mathrm{sp}^{2}$ ratio has been detailed previously. ${ }^{15,16}$ To minimize carbon contamination and irradiation beam damages, (S)TEM experiments were performed at liquid nitrogen temperature.

\section{PL emission/excitation/kinetics}

Photoluminescence emission, excitation as well as decay kinetics, and bleaching effects were studied by steady state and time resolved PL spectroscopies. Steady state PL spectra under vacuum ultraviolet (VUV) excitation were measured at room temperature by an ACTON single-beam spectrophotometer (model SP150) working in the $\mathrm{N}_{2}$ flux (typically $60 \mathrm{l} / \mathrm{min}$ ). The excitation light source is given by a $30 \mathrm{~W} \mathrm{D}_{2}$ lamp and selected by a first monochromator with 1200 grooves $/ \mathrm{mm}$, blazed at $150 \mathrm{~nm}$, and a slit resolution of $3 \mathrm{~nm}$. The luminescence is dispersed by a second monochromator (600 grooves $/ \mathrm{mm}$, blaze at $500 \mathrm{~nm}$, slit resolution of $5 \mathrm{~nm}$ ) and detected by a photomultiplier. The emission spectra were corrected for the monochromator dispersion, while the excitation spectra were corrected for the spectral efficiency of the exciting light, using a sodium salicylate sample as a reference.

Time-resolved PL spectra were performed at room temperature in front-scattering geometry. Pulsed excitation light (pulse width $\sim 5 \mathrm{~ns}$, repetition rate $10 \mathrm{~Hz}$ ) was provided by a VIBRANT OPOTEK optical parametric oscillator laser system, pumped by the third of a Nd:YAG laser harmonic $(354 \mathrm{~nm} / 3.50 \mathrm{eV})$. The laser emission could be varied from $400 \mathrm{~nm}(3.1 \mathrm{eV})$ to $210 \mathrm{~nm}(5.90 \mathrm{eV})$; the beam intensity was monitored by a pyroelectric detector and was kept at $\sim 0.15$ $\mathrm{mJ} / \mathrm{pulse}$. The luminescence emitted by the sample was dispersed by a spectrograph (SpectraPro 2300i, PI/Acton, $300 \mathrm{~mm}$ focal length) equipped with a grating with 150 grooves $/ \mathrm{mm}$ and blazed at $300 \mathrm{~nm}$, and the spectral slit resolution was set to $20 \mathrm{~nm}$. The detector used an intensified charge coupled device camera driven by a delay generator (PIMAX Princeton instruments) for acquiring the emitted light in a time window Delta delayed TD from the laser pulse. The emission spectra were corrected for the dispersion of a monochromator. 
Steady state and time-resolved PL measurements were also performed using an optical system on the base of nitrogen laser for excitation $(\lambda=337.1 \mathrm{~nm}$, pulse duration $9 \mathrm{~ns}$, pulse repetition frequency $f=80 \mathrm{~Hz}$ ). A delay time of about $1 \mathrm{~ns}$ from the start of laser pulse and a strobe gate of about $0.1 \mathrm{~ns}$ were used for time-resolved measurements. Such method allows examining the relative contribution of emission centers with different optical response times in the broad-band emission spectrum.

\section{RESULTS AND DISCUSSION}

\section{A. XPS and (S)TEM analyses}

XPS spectra of the fumed silica precursor and the sample of phenylsilica treated at $600{ }^{\circ} \mathrm{C}$ are presented in the supplementary material [Figs. S1(a) and S1(b)]. The results of elemental quantification are presented in Table I. The effect of the chemical/thermal treatment on the samples can be clearly seen as it leads to a strong increase in the carbon concentration. The effect of the gas cluster ion beam (GCIB) etching on the XPS survey has been examined to extract the effect of carbon contamination adsorbed on the surface of fumed silica. The etching leads to a decrease in two percent of the $\mathrm{O}$ atomic concentration followed by a slight increase in the $\mathrm{C}$ atomic concentration. This slight increase in carbon after etching has been observed for all the samples and could be related to carbon diffusion from bottom to the top layers due to the local increase in temperature induced by the ionic bombardment and low thermal conductivity of the nanopowder. It should be noted that no variation of the Si2p and O1s spectra has been observed under GCIB etching.

$\mathrm{C} 1 \mathrm{~s}$ spectrum of fumed silica is composed of a main peak at $285 \mathrm{eV}(\mathrm{C}-\mathrm{C} / \mathrm{C}=\mathrm{C})$ and a high energy shoulder that can be fitted by two bands (Fig. S1). These bands are obviously related to oxygen in the form of carbonyl/carboxyl/alkoxy groups in organic pollutions and adsorbed $\mathrm{CO} / \mathrm{CO}_{2}$. GCIB etching resulted in the weakening of an oxygen related shoulder [Fig. S1(b)]. Here, we are not focusing on the identification of pollutions in fumed silica but demonstrate that local chemistry of the carbon-based materials can be modified even after soft gas cluster ion beam etching. Consequently, only the data acquired before GCIB etching are considered and discussed.

$\mathrm{Si} 2 \mathrm{p}, \mathrm{C} 1 \mathrm{~s}$, and $\mathrm{O} 1 \mathrm{~s}$ spectra of $\mathrm{SiO}_{2}: \mathrm{C}$ sample annealed at $600{ }^{\circ} \mathrm{C}$ are illustrated in Fig. S2. Si2p and O1s peaks are symmetrical without evident signs of multicomponent nature indicating that main contribution to these peaks comes from the

TABLE I. XPS quantification obtained of the fumed silica precursor and the sample treated at $600^{\circ} \mathrm{C}$.

\begin{tabular}{lcc}
\hline \hline & $\begin{array}{c}\text { Fumed silica } \\
\text { precursor }\end{array}$ & $600{ }^{\circ} \mathrm{C}$ \\
\hline $\mathrm{Si} \mathrm{(at.} \mathrm{\% )}$ & 38.3 & 30.3 \\
$\mathrm{O}($ at. \%) & 55.2 & 41.2 \\
$\mathrm{C}$ (at. \%) & 6.6 & 28.4 \\
Energy difference & 429.4 & 429.3 \\
between Si 2p and O 1s lines (eV) & & \\
\hline \hline
\end{tabular}

$\mathrm{SiO}_{2}$ matrix. The energy difference between the $\mathrm{Si} 2 \mathrm{p}$ $(103.6 \mathrm{eV})$ and $\mathrm{O} 1 \mathrm{~s}(533,1 \mathrm{eV})$ can also be used as the indicator of the local chemistry of the silica. ${ }^{15}$ The obtained values are similar for the precursor and the sample treated at $600^{\circ} \mathrm{C}$, and they are close to the reference values obtained on fumed silica $(429.5 \mathrm{eV}) .{ }^{17}$ Contributions of local Si-C surface bonds, if present, would be close to $102 \mathrm{eV}$, i.e., in low energy part of Si2p spectrum. ${ }^{18}$ However, no additional contribution can be distinguished at the low energy Si2p spectrum.

In contrast to $\mathrm{Si} 2 \mathrm{p}$ and $\mathrm{O} 1 \mathrm{~s}$, the $\mathrm{C} 1 \mathrm{~s}$ peak is obviously multicomponent with a dominant contribution from the peak at $284.9 \mathrm{eV}(\mathrm{C}-\mathrm{C} / \mathrm{C}=\mathrm{C}$ bonds $)$ and a minor, but significant, high energy component at $286.1 \mathrm{eV}$, which can be assigned to carbon-oxygen bonds. ${ }^{19,20}$ The small peak at $290 \mathrm{eV}$, highlighted by a red arrow [Fig. S2(b)], is more likely to correspond to the $\pi \rightarrow \pi^{*}$ shake-up satellite that is inherent to conjugated systems ("graphite-like" structure). Oxygen related contribution in C1s is still present after GCIB etching and then it can be assigned to the specific structure of carbon precipitates. Identification of $\mathrm{O}-\mathrm{C}$ contribution in the $\mathrm{O} 1 \mathrm{~s}$ spectrum is hampered by the dominant contribution of the $\mathrm{O}-\mathrm{Si}$ peak from the $\mathrm{SiO}_{2}$ matrix and overlapping of the $\mathrm{O}-\mathrm{Si}$ and $\mathrm{O}-\mathrm{C} / \mathrm{O}=\mathrm{C}$ peaks. In any case, it is hard to associate carbon-oxygen bonds as $\mathrm{C}-\mathrm{OH}$ terminating bonds or $\mathrm{C}-\mathrm{O}-\mathrm{Si}$ interface bridging bonds between carbon precipitates and the silica surface.

A typical STEM image of the pristine fumed silica is shown in Fig. 1(a). Two different kinds of nanoparticles can be highlighted in this image. Minor fraction of the sample is composed of bigger particles with a diameter of about $30-40 \mathrm{~nm}$, while most of the sample consists of smaller nanoparticles with a diameter of about $8-10 \mathrm{~nm}$ [Fig. 1(b)]. The smallest nanoparticles are sintered and both kinds of nanoparticles are amorphous. A typical EELS spectrum of the smallest nanoparticles is displayed in Fig. 1(c). The Si-L and $\mathrm{O}-\mathrm{K}$ edges can be clearly highlighted on the spectrum around 105 and $530 \mathrm{eV}$, respectively. No signs of carbon (C$\mathrm{K}$ around $290 \mathrm{eV}$ ) were detected in the spectrum. The Si-L fine structures [see the inset of Fig. 1(b)] match the fine structures of $\mathrm{SiO}_{2} \cdot{ }^{21-23} \mathrm{In}$ addition, it should be noted that the EELS response of the smallest and biggest nanoparticles is similar. Thus, this means that the only differences between the two kinds of nanoparticles regard their size and morphology and not their composition.

Figure 2(a) shows the STEM micrograph of the samples annealed at $600{ }^{\circ} \mathrm{C}$. Both kinds of nanoparticles are present in this sample. This means that the morphological features of the silica host matrix remain unchanged after chemical and thermal treatments. The C-K edge can now be distinguished in some areas of the sample [Fig. 2(c)]. The striking difference with the silica precursor is the presence of carbon-rich areas that are now highlighted in the elemental map and can be identified as carbon precipitates on the silica surface [Fig. 2(c)]. From the carbon elemental map, the size of the Cprecipitates has been determined and is between 2 and $6 \mathrm{~nm}$. The atomic concentration of carbon can reach up to $50 \%$ in some regions of the sample. In addition, no evident differences can be highlighted in the Si-L and O-K fine structures of the carbon-rich and carbon-deficient area of the sample 


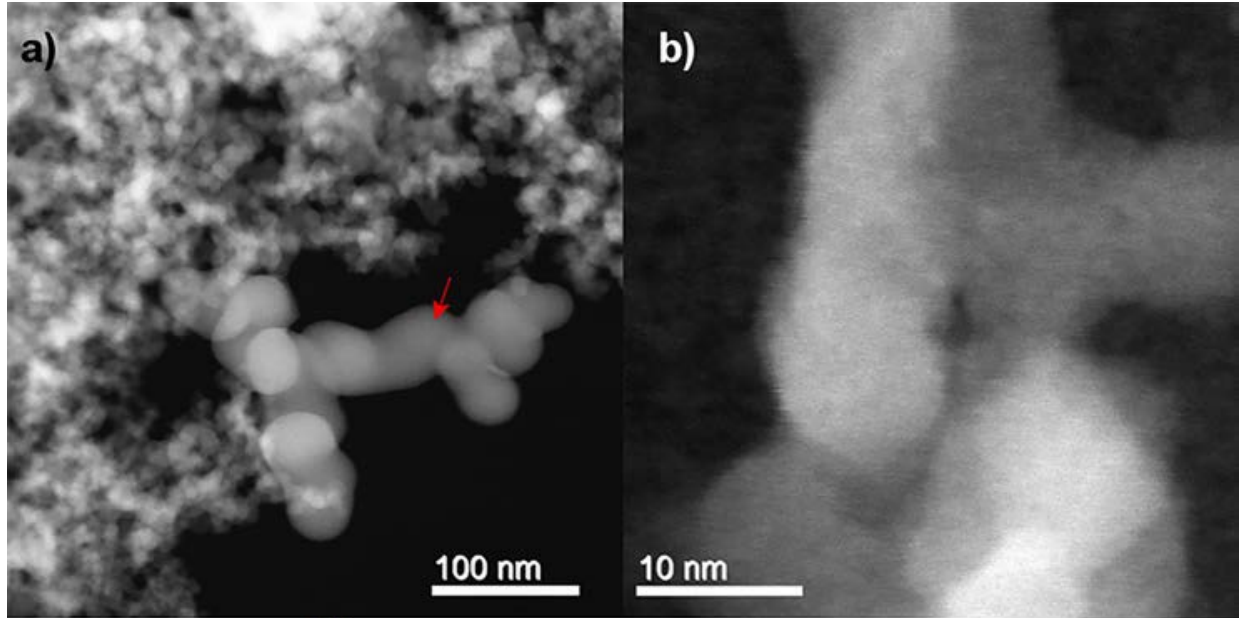

c)

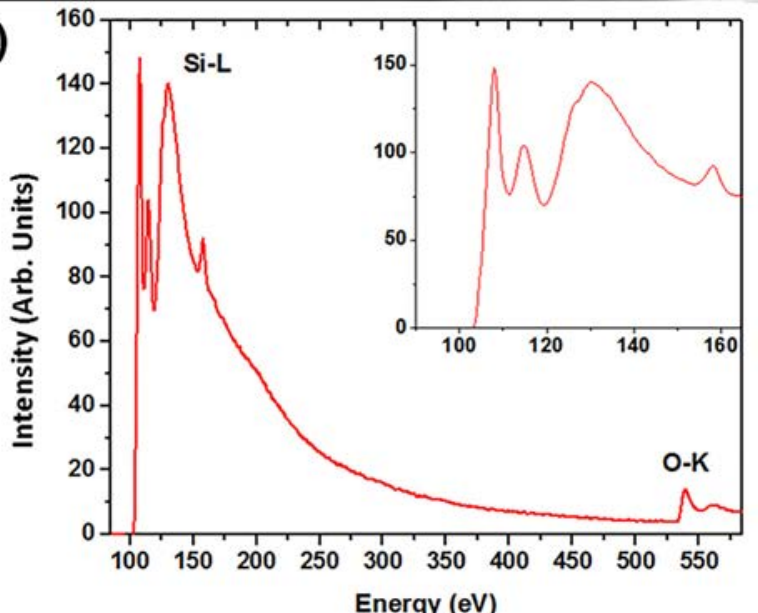

FIG. 1. (a) Typical STEM HAADF micrograph of the fumed silica precursor. The red arrow highlights the minor fraction corresponding to the biggest nanoparticles. (b) HR-STEM HAADF micrograph of the smallest nanoparticles. (c) Typical EELS spectrum taken on the smallest nanoparticles. The inset shows an enlarged region closed to the Si-L edge.
[Fig. 2(c) and inset] although more detailed studies would be needed to clarify possible contribution from Si-C and C-O local bonds. Figure 3 shows a monochromated EELS spectrum (centered in the $\mathrm{C}-\mathrm{K}$ edge) recorded on the sample annealed at $600{ }^{\circ} \mathrm{C}$. The spectrum is the characteristic of an amorphous carbon although fine structures above $290 \mathrm{eV}$ (see red arrows in Fig. 3) highlight some degree of graphitization and local order. ${ }^{15}$ Finally, the carbon $\mathrm{sp}^{2}$ ratio has been estimated from the TEM-EELS analysis and is found to be close to $80 \%$.

\section{B. Interatomic bonds}

FTIR transmission spectra of pristine fumed silica, phenylsilica, and annealed phenylsilica are presented in Fig. 4. The silicon oxide structure in pristine fumed silica is represented by the $\mathrm{Si}-\mathrm{O}-\mathrm{Si}$ related band at $800 \mathrm{~cm}^{-1}$ and $1000-1200 \mathrm{~cm}^{-1}$ with a low-frequency shoulder at $970 \mathrm{~cm}^{-1}$ (stretching $\mathrm{Si}-\mathrm{OH}$ ) (Fig. 4, spectrum 1). The $1960 \mathrm{~cm}^{-1}$ and $1870 \mathrm{~cm}^{-1}$ paramount bands, clearly observed in the spectrum of pristine silica, correspond to the overtone/combination of vibration modes inherent to nanosilicas with high specific surface area. ${ }^{24}$ The broad absorption band in the range of $3000-3800 \mathrm{~cm}^{-1}$ and relatively narrow band at $1630 \mathrm{~cm}^{-1}$ originated from adsorbed water molecules and correspond to $\mathrm{O}-\mathrm{H}$ stretching and bending vibration modes, respectively. ${ }^{25}$ However, it may include strongly disturbed surface hydroxyls forming strong hydrogen bonds. The high frequency shoulder of this band at about $3640 \mathrm{~cm}^{-1}$ is commonly assigned to inner surface silanols. ${ }^{24}$

Upon chemical modification, well-defined IR bands associated with $\mathrm{C}-\mathrm{H}$ bonds in benzene rings at $3000-3100 \mathrm{~cm}^{-1}$ $\left[\mathrm{C}\left(s p^{2}\right)-\mathrm{H}_{\mathrm{n}}\right.$ stretching] as well as at $690 \mathrm{~cm}^{-1}$ and $730 \mathrm{~cm}^{-1}$ [out-of-plane bending $\mathrm{C}\left(s p^{2}\right)-\mathrm{H}_{\mathrm{n}}$ ] are observed, while $\mathrm{C}\left(s p^{3}\right)$ $\mathrm{H}_{\mathrm{n}}$ bonds in methoxy groups are manifested by a set of narrow bands at $2800-3000 \mathrm{~cm}^{-1}$ (Fig. 4, spectrum 2). ${ }^{14}$ The structural skeleton of benzene rings of phenyl groups give rise to the narrow bands at $1430 \mathrm{~cm}^{-1}$ and $1590 \mathrm{~cm}^{-1}$ accompanied by "benzene fingers" at $1700-2000 \mathrm{~cm}^{-1}$ due to overtone/ combination vibrations. The presence of $\mathrm{Si}-\mathrm{O}-\mathrm{C}$ bonding, presumably available on the surface of phenylsilica, cannot be verified as its absorption is expected in the range of $1000-1200 \mathrm{~cm}^{-1}$ (Refs. 25 and 26) i.e., in the spectral range of the strong absorption of the silica host matrix. It is worth noting that after chemical modification, the relative contribution of adsorbed moisture (3000-3500 $\mathrm{cm}^{-1}$ broad band) decreased strongly in comparison to the $3640 \mathrm{~cm}^{-1}$ band, which corresponds to isolated surface silanol groups (Fig. 4, spectrum 2). These encapsulated surface groups are inaccessible for liquid reactants and remains undisturbed after chemical modification. Strong reduction of adsorbed water molecules may indicate the conversion of the silica surface from hydrophilic to hydrophobic. After annealing at $500{ }^{\circ} \mathrm{C}$, silanol groups are removed from the material (Fig. 4, spectrum 3), while at higher annealing temperatures, they are well detectable (Fig. 4, spectra 4,5). 


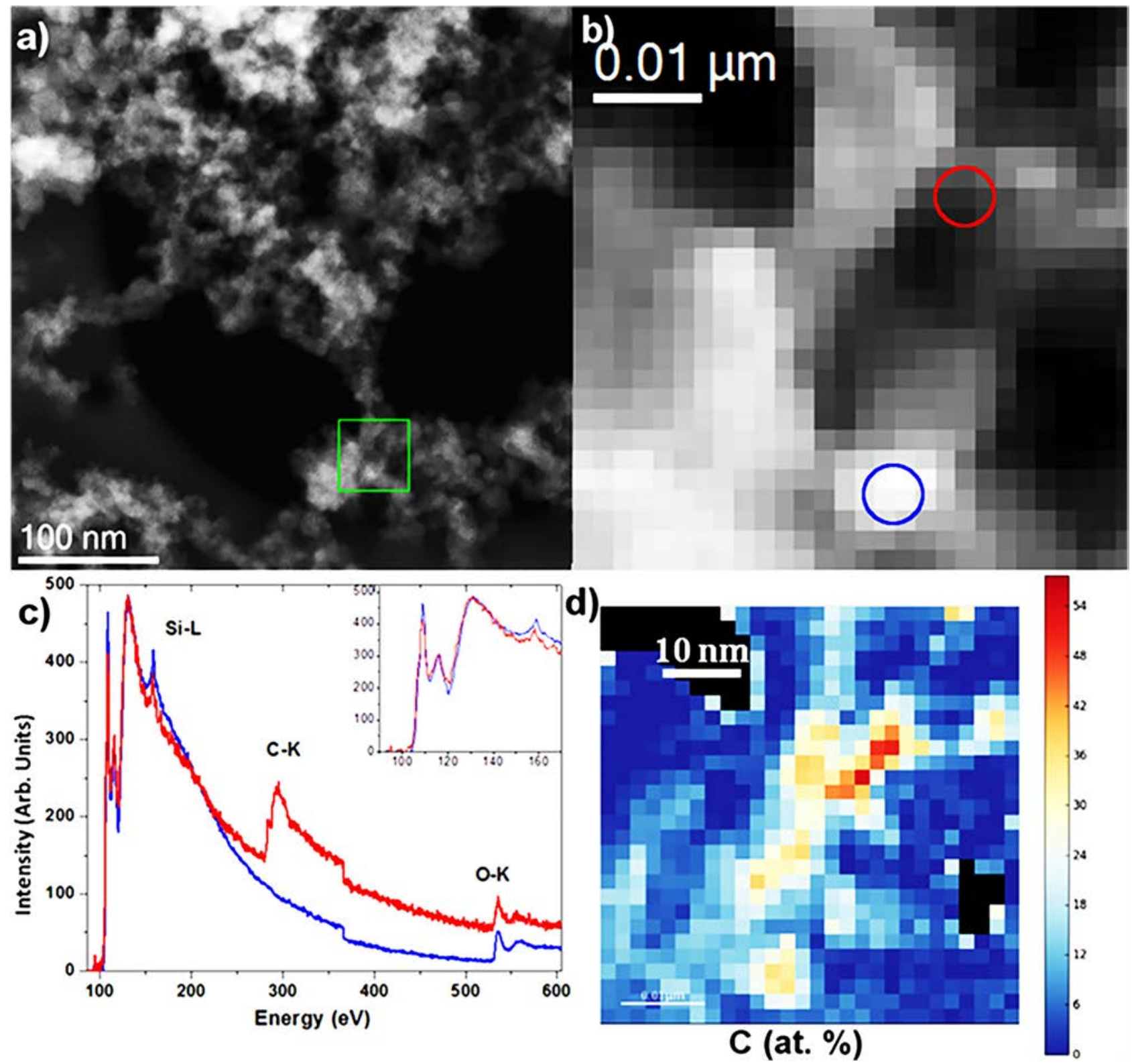

FIG. 2. (a) STEM micrograph of the sample annealed at $600^{\circ} \mathrm{C}$. The green square highlights the area used for the SR-EELS analysis; (b) STEM dark field micrograph recorded at the same time that the SR-EELS data. The red and blue circles correspond to the area in which the red and blue EELS spectra of (c) have been taken. (d) Map of the atomic concentration of carbon as determined from the EELS quantification.

Detailed spectral features of IR absorption bands, reflecting the reconstruction of $\mathrm{C}-\mathrm{H}$ and $\mathrm{C}=\mathrm{C}$ bonds, are presented in Figs. S3(a) and S3(b) of the supplementary material, respectively. The main effect of the annealing at $500^{\circ} \mathrm{C}$ is a strong reduction of the $\mathrm{C}\left(s p^{3}\right)-\mathrm{H}$ band $\left(2800-3000 \mathrm{~cm}^{-1}\right)$, indicating a decomposition/desorption of methyl groups. Phenyl groups are still being intact at such temperature as it can be seen by the corresponding $\mathrm{C}\left(s p^{2}\right)-\mathrm{H}$ and $\mathrm{C}=\mathrm{C}$ absorption bands. Destruction of benzene rings is evident after annealing at $600{ }^{\circ} \mathrm{C}$. This is indicated by a reduction of the absorption at $3000-3100 \mathrm{~cm}^{-1}$ [Fig. S3(a)] as well as by the vanishing of the narrow $1430 / 1590 \mathrm{~cm}^{-1}$ doublet [Fig. S3(b)]. Destruction of benzene rings is accompanied by the presence of a broad band at $1600-1610 \mathrm{~cm}^{-1}$. This broad band is likely due to disordered $\mathrm{C}=\mathrm{C}$ bonds, which can be interpreted as the formation of amorphous carbon clusters [Fig. S3(b)]. No FTIR fingerprints of benzene rings are detected in the samples after annealing at higher temperature. This indicates their full conversion into amorphous pyrolytic carbon. Our attempts to identify pyrolytic carbon by Raman scattering using laser excitations at either $488 \mathrm{~nm}$ or $514 \mathrm{~nm}$ were not successful due to the strong background of the PL excited by the laser probe. As it has been demonstrated previously, carbon related Raman scattering can be detected in phenylsilica after annealing at temperature as high as $800^{\circ} \mathrm{C} .{ }^{27}$ These samples are black in colour, not luminescent under UV/VIS excitation, and well-defined Raman scattering spectra composed of typical D- and G-bands can be detected.

\section{PL emission}

Under thermal treatment, the color of the powder changed gradually with increasing of the temperature from white to dark brown. This evolution was accompanied by the 


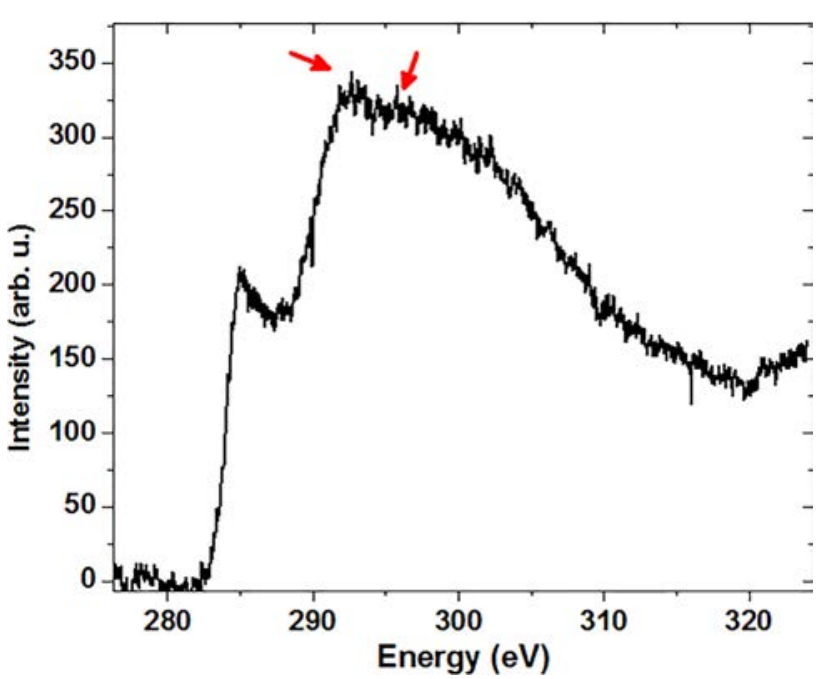

FIG. 3. (a) STEM EELS spectrum recorded on the sample annealed at $600^{\circ} \mathrm{C}$ with the monochromator on (resolution $=0.3 \mathrm{eV}$ ). The red arrows highlight some graphitic fine structures.

development of the photoluminescence. Figure S4 shows pictures of the light emission of the annealed samples under $408 \mathrm{~nm}$ LED radiation.

The effects of the chemical modifications and of the thermal treatments on the luminescence spectral properties of silica nanoparticles are evidenced by the emission PL spectra reported in Fig. 5. Figure 5(a) illustrates the PL spectra of fumed silica before (spectrum 1) and after chemical treatment (spectrum 2) under $260 \mathrm{~nm}(4.77 \mathrm{eV})$ excitation. As shown in the zoom of Fig. 5(a), as-received silica nanoparticles exhibit the well-known blue band centered around $440 \mathrm{~nm}(2.8 \mathrm{eV})$ with full width at half maximum (FWHM) $\approx 60 \mathrm{~nm}(0.8 \mathrm{eV})$. The origin of this emission is still a matter of debate, ${ }^{28}$ and the most endorsed hypothesis associates it

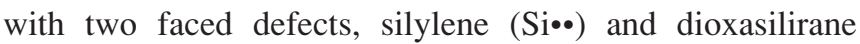
$\left(\mathrm{Si}\left(\mathrm{O}_{2}\right)\right)$, localized at the surface of a silica nanoparticle. ${ }^{29} \mathrm{~A}$ minor component around $354 \mathrm{~nm}(3.5 \mathrm{eV})$ is also evident in the spectrum, which has been previously attributed to hydrocarbon contamination $^{30}$ or surface silanols $(\mathrm{Si}-\mathrm{OH}) .^{31}$

Chemical modifications with PhTMS induce the apparition of an UV band centered around $335 \mathrm{~nm}(3.7 \mathrm{eV})$ with a $\mathrm{FWHM} \approx 50 \mathrm{~nm}(0.7 \mathrm{eV})$. It dominates the whole spectrum and almost completely hinders the blue band [Fig. 5(b), spectrum 1]. This band might correspond to the excimer transitions of phenyl groups closely located on the silica surface. ${ }^{32-34} \mathrm{~A}$ similar PL band was also observed in poly(diphenylsilylcarbodiimide $)^{12}$ and attributed to phenyl excimers.

Thermal treatments of phenylsilica induce remarkable changes in their PL spectra [Fig. 5(b)]. After $500^{\circ} \mathrm{C}$, the emission is peaked around $370 \mathrm{~nm}(3.3 \mathrm{eV})$ and also presents a component at lower energy. At higher treatment temperature, we observe a red shift and a decrease in the PL intensity: after $600{ }^{\circ} \mathrm{C}$, the emission consists of a single band centered around $450 \mathrm{~nm}(2.75 \mathrm{eV})$ with a FWHM close to $0.7 \mathrm{eV}$, while after $650{ }^{\circ} \mathrm{C}$ the PL is centered around $490 \mathrm{~nm}$ $(2.5 \mathrm{eV})$ with a FWHM close to $0.8 \mathrm{eV}$. We note that the PL is no longer observed in these experiments after thermal treatments at $700{ }^{\circ} \mathrm{C}$ and higher when using UV excitation

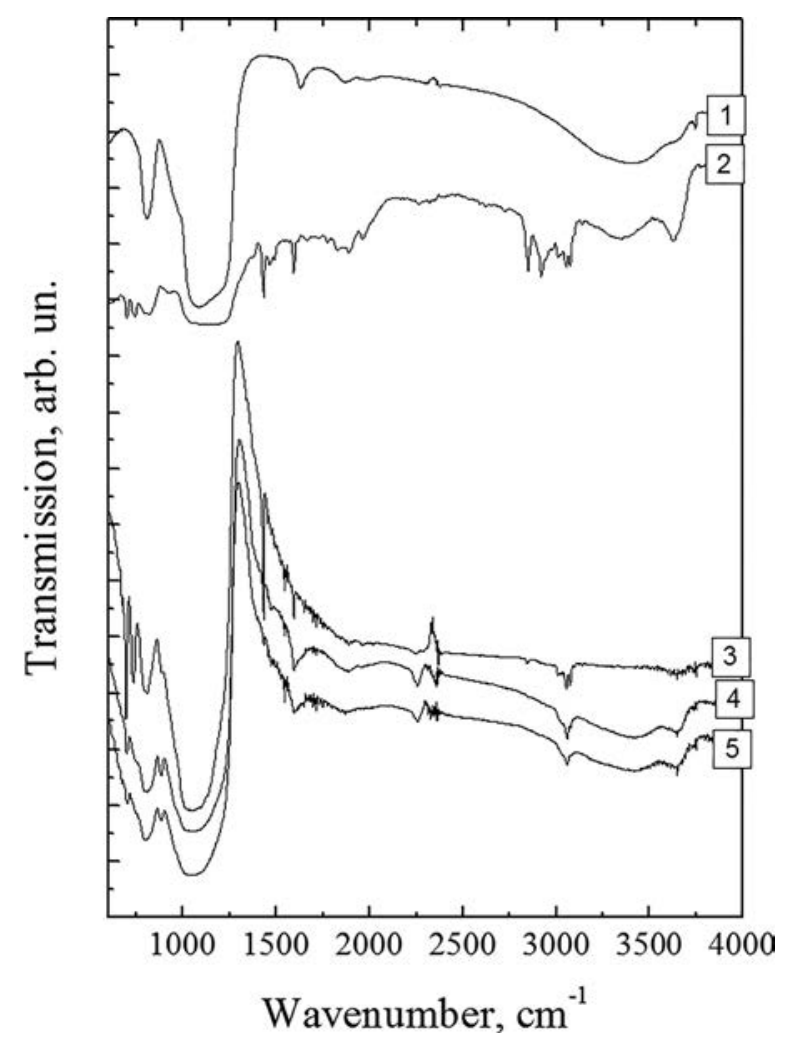

FIG. 4. FTIR spectra: pristine fumed silica (1); chemically modified fumed silica (phenylsilica) (2); phenylsilica thermally treated at $500^{\circ} \mathrm{C}(3), 600{ }^{\circ} \mathrm{C}$ (4), and $650^{\circ} \mathrm{C}(5)$.

although it was demonstrated previously ${ }^{27}$ that noticeable emission can be detected in the samples after annealing at $700{ }^{\circ} \mathrm{C}$ when excited by visible and/or infrared laser.

Changes of PL spectra are also evidenced under excitation at $355 \mathrm{~nm}(3.49 \mathrm{eV})$, limited to the visible range [Fig. $5(c)$ ]. Silica nanoparticles in pristine fumed silica emit the blue band centered on $440 \mathrm{~nm}(2.8 \mathrm{eV})$. A similar spectral distribution of emission, but showing significantly larger intensity, can be observed for the phenylsilica annealed at $500{ }^{\circ} \mathrm{C}$. At higher annealing temperature, the PL shifts at lower energy and its intensity decreases. We note that after $650{ }^{\circ} \mathrm{C}$, the emission is peaked around $500 \mathrm{~nm}(2.5 \mathrm{eV})$ as observed under excitation at $260 \mathrm{~nm}(4.77 \mathrm{eV})$.

To verify the relation of the light emission with pyrolytic carbon in the powder, all the carbonized samples were annealed in a flow of oxygen at $600{ }^{\circ} \mathrm{C}$ for $1 \mathrm{~h}$. After such treatment, the color of all samples changed from brown to the initial white of the pristine silica accompanied by full quenching of PL. This indicates the removal of the carbon from the samples by oxidation mechanisms and consequently, the photoluminescence quenched down below the detection limit. This observation confirms that carbon precipitates, formed during the pyrolytic decomposition of organic carbon, play a key role in light emission of carbonized silica in the ultraviolet (UV) and visible (VIS) spectral range.

\section{PL excitation}

The excitation PL properties of the samples are summarized in Fig. 6. This characterization was limited to the 

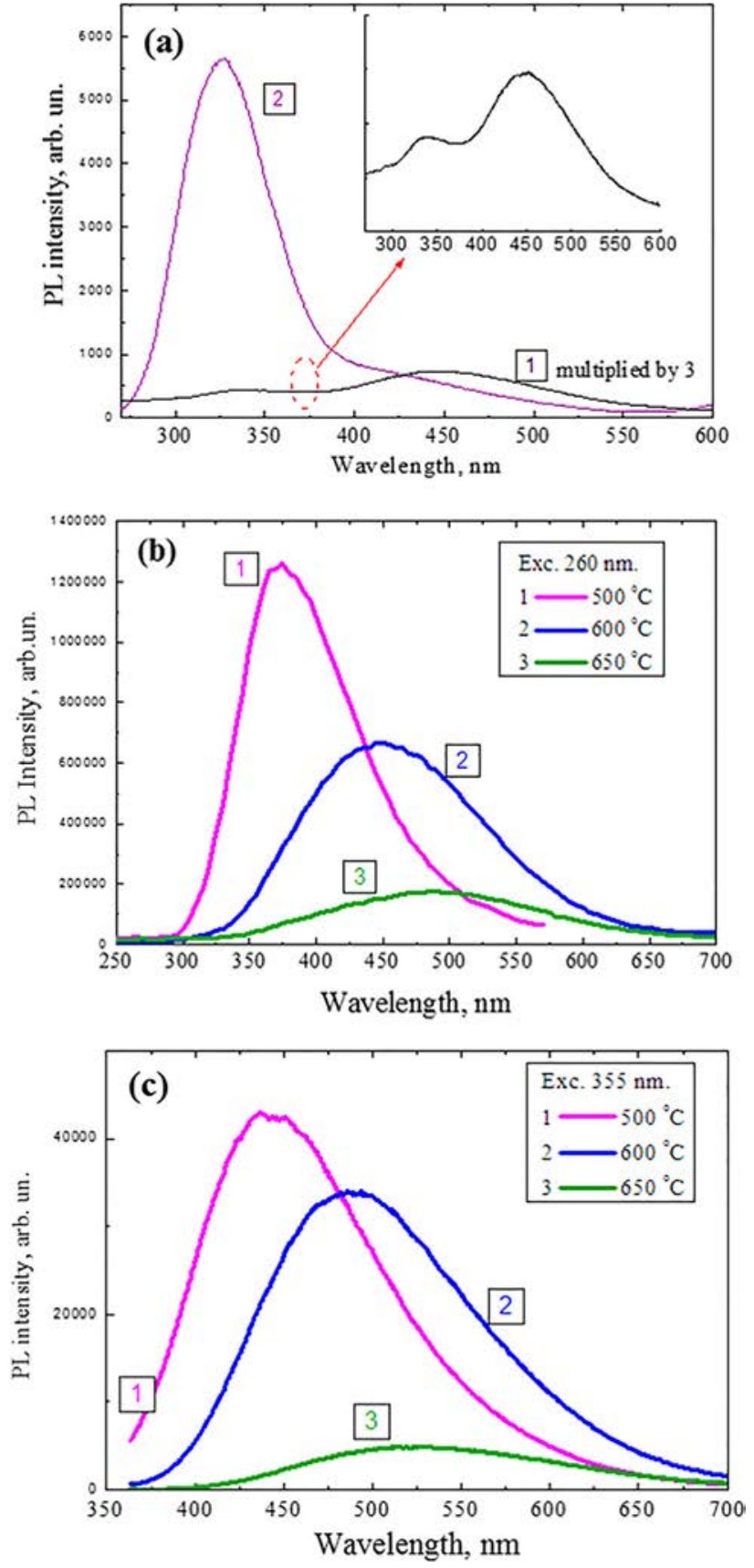

FIG. 5. (a) PL spectra of pristine fumed silica before (spectrum 1) and after chemical treatment by PhTMS (phenylsilica. spectrum 2) under excitation $260 \mathrm{~nm}$; the inset illustrates magnified PL spectrum of pristine silica; (b) PL spectra of phenylsilica after thermal annealing at $500^{\circ} \mathrm{C}(1), 600^{\circ} \mathrm{C}(2)$, and $650^{\circ} \mathrm{C}$ (3) under excitation $200 \mathrm{~nm}$; (c) PL spectra under excitation $355 \mathrm{~nm}$ (3.49 eV): $500^{\circ} \mathrm{C}(1), 600^{\circ} \mathrm{C}(2)$, and $650^{\circ} \mathrm{C}(3)$.

samples with the highest PL intensity, i.e., phenylsilica before annealing [Fig. 6(a)] and annealed at $500^{\circ} \mathrm{C}[\mathrm{Fig}$. 6(b)] and $600{ }^{\circ} \mathrm{C}$ [Fig. 6(c)].

The excitation spectra of phenylsilica are independent of the wavelength within the emission band and contain a well-defined band between 240 and $280 \mathrm{~nm}(4.4-5.7 \mathrm{eV})$, with a maximum of about $266 \mathrm{~nm}(4.7 \mathrm{eV})$. The independence of excitation band parameters on the emission wavelength indicates a well-defined structure and energy states in corresponding emission sites, which are inherent to molecular-like centers. The excitation band in the samples annealed at $500{ }^{\circ} \mathrm{C}$ and higher is significantly broadened, with a peak being shifted to the low-energy. The maximum intensity of emission at $380 \mathrm{~nm}(3.3 \mathrm{eV})$ is observed under excitation by $290 \mathrm{~nm}(4.3 \mathrm{eV})$ radiation, with a minor highenergy shoulder at $260 \mathrm{~nm}(4.8 \mathrm{eV})$. This shoulder is dominated by a high-energy emission part [Fig. 6(b), spectra 3 and 4], which can be interpreted as the domination of the emission by phenyl-groups that are still present in this sample (see Fig. S3). Further broadening and low frequency shift of excitation band to $320 \mathrm{~nm}(3.9 \mathrm{eV})$ are observed in the sample annealed at $650^{\circ} \mathrm{C}$. A significant shift of the
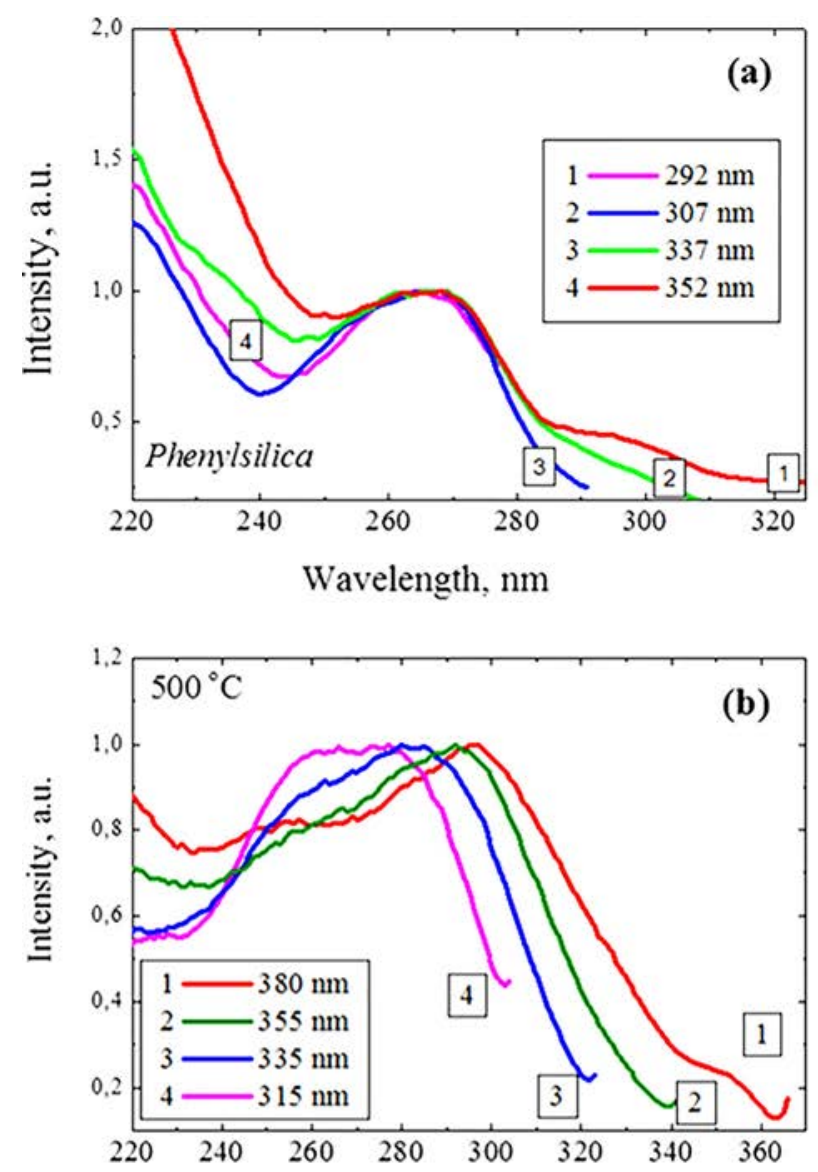

Wavelength, nm

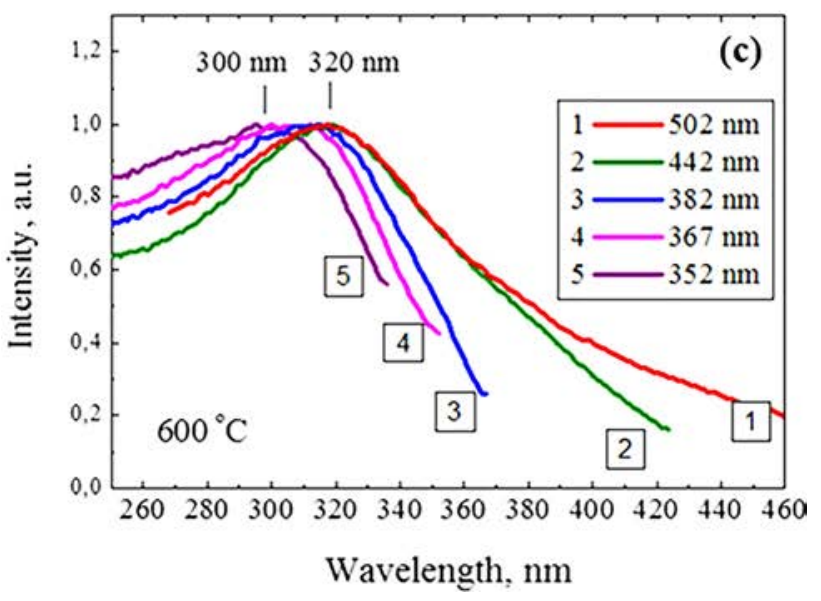

FIG. 6. Excitation PL spectra of phenylsilica before (a) and after annealing at $500^{\circ} \mathrm{C}\left(\right.$ b) and $600^{\circ} \mathrm{C}(\mathrm{c})$. 
excitation band (from $320 \mathrm{~nm}$ to $300 \mathrm{~nm}$, i.e., about $0.3 \mathrm{eV}$ ), with a decrease in the emission wavelength in this sample, indicates an inhomogeneous nature and a broad energy distribution of corresponding emission centers.

\section{E. PL kinetics}

The PL bands have been characterized by their decay curves from which characteristic lifetimes were estimated. Figure S5 shows the typical decay curves for characteristic emission wavelengths excited by $260 \mathrm{~nm}(4.8 \mathrm{eV})$. Decay curves in all samples deviate from a pure exponential function. This behavior is common to defects in amorphous systems. ${ }^{35}$ Here, we only measure the lifetime $(\tau)$, which is the time to reduce the PL intensity to a factor of $1 / \mathrm{e}$. We found $\tau$ $=4.0 \pm 0.5 \mathrm{~ns}$ for $326 \mathrm{~nm}(3.8 \mathrm{eV})$ emission in as-prepared phenylsilica, and $\tau=2.0 \pm 0.5 \mathrm{~ns}$ for the band at $376 \mathrm{~nm}$ $(3.3 \mathrm{eV})$ in phenylsilica after treatments at $\mathrm{T}=500^{\circ} \mathrm{C}$. Based on the significant difference in decay time, it can be suggested that UV bands in these samples have different structural nature. The blue band at $443 \mathrm{~nm}(2.8 \mathrm{eV})$ observed in pristine fumed silica decays with a lifetime $\tau=3.5 \pm 0.3 \mathrm{~ns}$. Similar decay kinetics was found for $486 \mathrm{~nm}(2.5 \mathrm{eV})$ emission in phenylsilica after treatment at $600{ }^{\circ} \mathrm{C}$, while the $506 \mathrm{~nm}(2.45 \mathrm{eV}) \mathrm{PL}$ band in phenylsilica after treatment at $650{ }^{\circ} \mathrm{C}$ decays with $\tau=3.0 \pm 0.3 \mathrm{~ns}$.

In order to examine the homogeneity of the emission spectra with respect to the lifetimes of the radiating centers, we measured the PL spectra of the samples at a steady-state and time-resolved conditions under excitation by $337 \mathrm{~nm}$ $(3.7 \mathrm{eV})$ laser with a laser pulse of $9 \mathrm{~ns}$. The stroboscopic detection system, with $1 \mathrm{~ns}$ delay from the beginning of laser pulse and strobe gate of about $0.1 \mathrm{~ns}$, has been used in timeresolved experiments. This allows extracting the contribution of emission centers with a shorter response time. The PL spectra of annealed samples measured in the steady state and time-resolved regimes are presented in Fig. 7. It can be seen that the steady-state and time-resolved spectra of the samples annealed at $500{ }^{\circ} \mathrm{C}$ and $650{ }^{\circ} \mathrm{C}$ are almost identical [Figs. 7 (a) and 7(c)], which indicates the good homogeneity of the corresponding radiating centers contributing to the PL band with respect to emission response time. In contrast, the PL band of the sample annealed at $600{ }^{\circ} \mathrm{C}$ exhibits strong inhomogeneity with almost equal contribution from "fast" and "slow" centers [Fig. 7(b)]. Subtracting the time-resolved spectrum from the steady-state yields a spectral distribution similar to the sample annealed at $650^{\circ} \mathrm{C}$ [Fig. 7 (b), spectrum 3]. From such comparison, it can be suggested that emission band of this sample is composed of at least two components corresponding to emission centers which have a structural nature similar to the one present in the samples annealed at $500^{\circ} \mathrm{C}$ and $650{ }^{\circ} \mathrm{C}$ (high-energy and low energy spectral parts, respectively).

It should be noted that minor degree of inhomogeneity of the PL band with respect to the radiation time can also be found in the PL bands of the samples after annealing at $500{ }^{\circ} \mathrm{C}$ and $650^{\circ} \mathrm{C}$. In both samples, the low-energy contribution slightly decreases under time-resolved measurements.
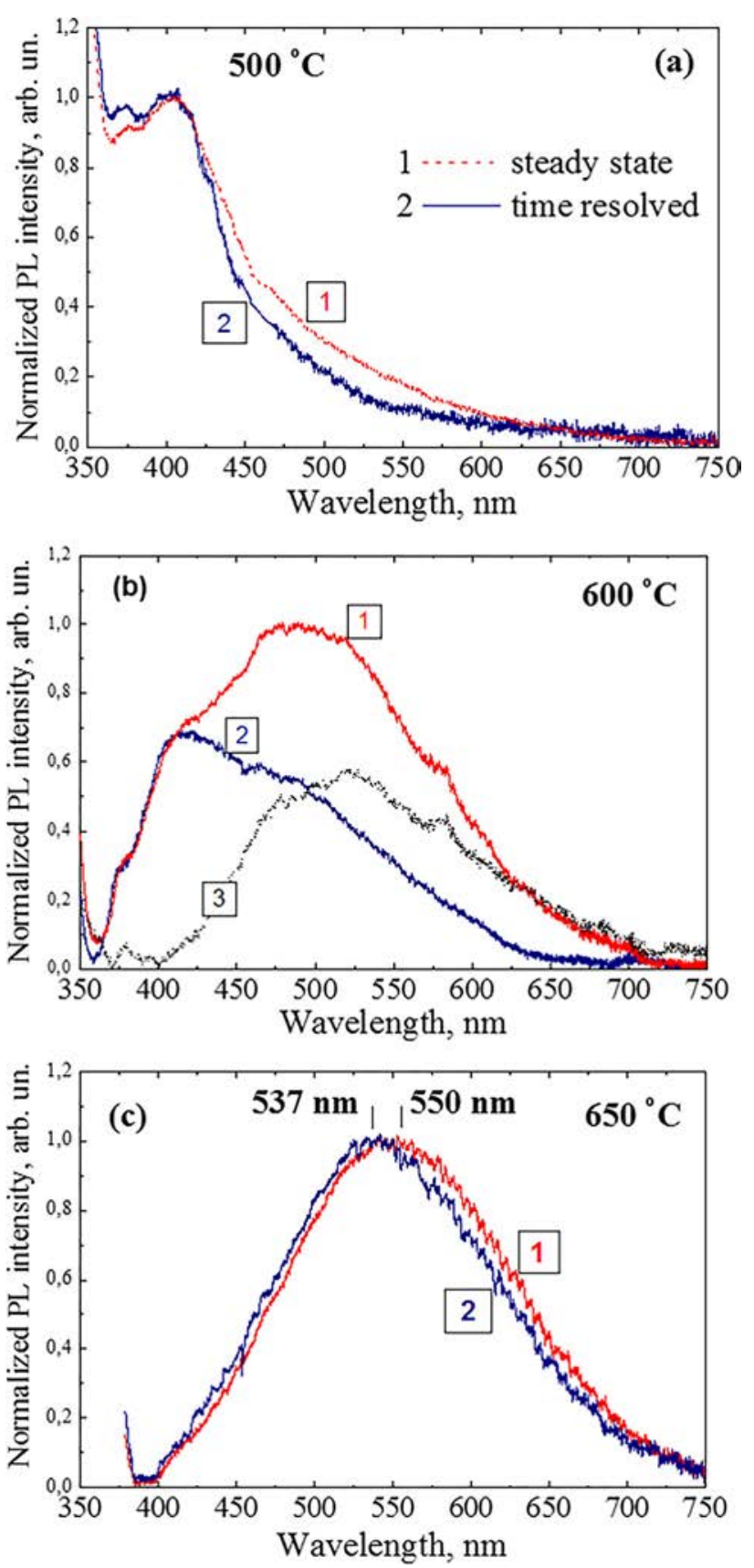

FIG. 7. Steady-state (red) and time resolved (blue) PL spectra: (a) $500^{\circ} \mathrm{C}$, (b) $600^{\circ} \mathrm{C}$, and (c) $650^{\circ} \mathrm{C}$. Spectrum 3 (dotted line) is the result of subtraction of spectrum 2 from spectrum 1. Excitation by $337 \mathrm{~nm}$.

This indicates a slower emission response of the low energy part of radiating center ensemble.

\section{F. PL bleaching}

PL examinations of the samples in atmospheric air exhibited obvious time-dependent PL extinction and spectral evolution. In contrast, PL measurements in nitrogen ambient showed no signs of bleaching of the emission under excitation radiation. Figure 8 shows the normalized PL spectra measured in nitrogen flow and in air. From comparison of the spectra, it can be concluded that high-energy PL emission is more sensitive to the bleaching effect. Such conclusion is confirmed by experiments on direct examination of 


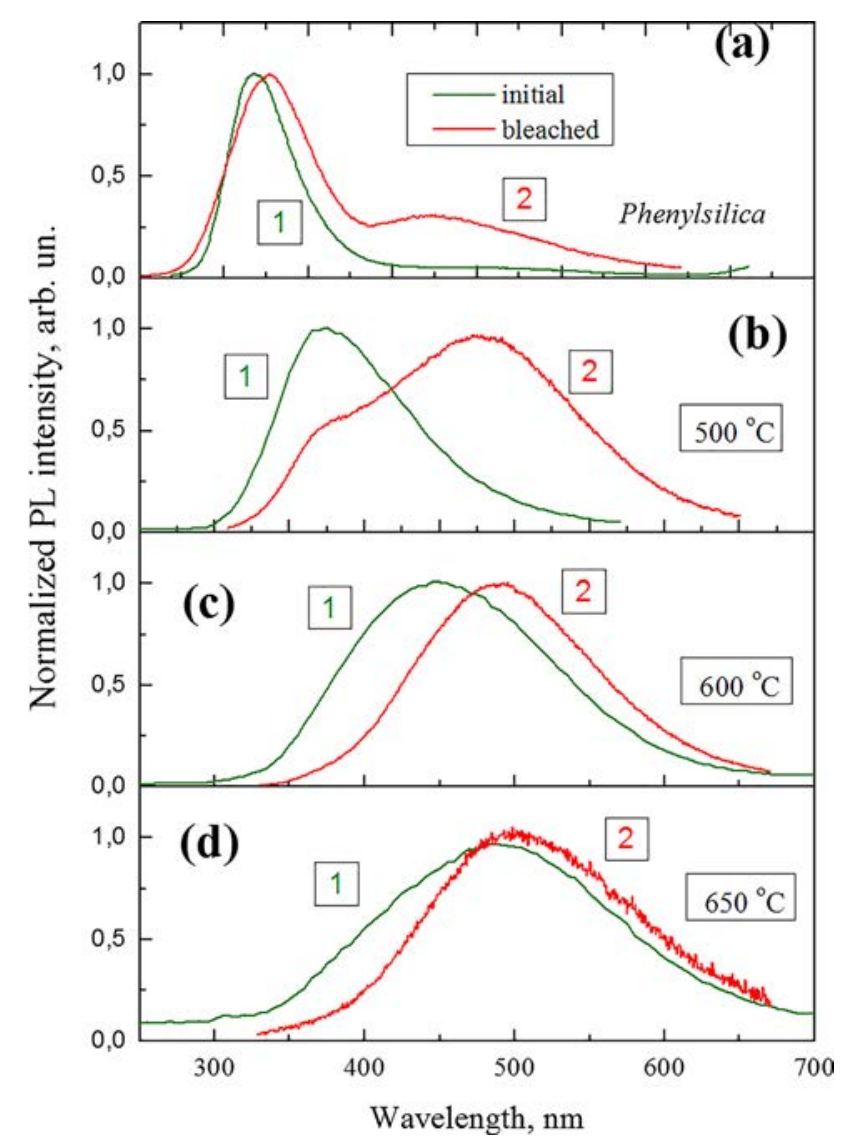

FIG. 8. Evolution of normalized emission intensity at $440 \mathrm{~nm}$ in the sample annealed at $600{ }^{\circ} \mathrm{C}$ (curve 1) and $530 \mathrm{~nm}$ emission in the sample annealed at $650^{\circ} \mathrm{C}$ (curve 2) under UV radiation of an $\mathrm{Hg}$ lamp.

bleaching dynamics using strong UV-radiation of an Hg-lamp as the radiation source. Figure S6 illustrates the evolution of normalized emission intensity at $440 \mathrm{~nm}$ in the sample annealed at $600{ }^{\circ} \mathrm{C}$ (curve 1) and $530 \mathrm{~nm}$ emission, and in the sample annealed at $650^{\circ} \mathrm{C}$ (curve 2) under UV radiation of the same powder. Exposure of the samples to UV radiation for $12 \mathrm{~min}$ (after saturation of both components) resulted in the decrease in $440 \mathrm{~nm}$ emission intensity by about $48 \%$, while the $530 \mathrm{~nm}$ emission is reduced by $23 \%$.

Bleaching of $\mathrm{PL}$ in $\mathrm{SiO}_{2}: \mathrm{C}$ powders in the presence of air is quite similar to the bleaching effect in porous $\mathrm{SiO}_{2}: \mathrm{C}$ layers reported in Ref. 6 . It was also found that there was no bleaching of $\mathrm{PL}$ in porous $\mathrm{SiO}_{2}$ :C during $\mathrm{PL}$ measurements in vacuum. ${ }^{36}$ Moreover, PL intensity in vacuum experiments demonstrated noticeable growth with time. Based on our study and by analogy with bleaching effects in porous $\mathrm{SiO}_{2}$ :C layers, it can be concluded that bleaching effects can be attributed to photo-induced destruction of light emission centers, namely, photo-oxidation of carbon clusters.

\section{DISCUSSION}

\section{A. Nature of the photoluminescence}

The analysis of the light-emitting properties of carbonized silica nanopowders should take into account the luminescent properties of the host silica matrix because many optically active intrinsic defects, including those emitting in visible spectrum, are known in silica based structures. ${ }^{37}$ Therefore, care must be taken to separate the fluorescent properties of the silica host matrix and the radiation associated with the incorporation of carbon. In our previous work, ${ }^{7}$ such analysis was carried out and it was well argued that the nature of photoluminescence in fumed silica carbonized by pyrolysis of surface methoxy groups is associated with the introduction of carbon but not with intrinsic defects.

A similar argumentation can be used in the case of phenylsilicas in this present study. In addition to that argumentation, we have shown that the removal of pyrolytic carbon from carbonized powder by heat treatment in oxygen completely quenches the corresponding PL. Photo-induced quenching of PL in the presence of oxygen can be considered as another evidence of carbon nature of light emission sites. Thus, the carbon nature of PL is well corroborated, but the question of the structural identification of light-emitting carbon-based centers remains open.

So far, in this paper, we considered the luminescent properties of carbonized powders in which phenyl groups were used as a building material in the pyrolytic carbonization process. However, it turns out that PL of materials on the base of carbonized fumed silica obtained using other carbon precursors possesses some common spectral features.

In the previous work, ${ }^{7}$ it was shown that when tetramethoxysilane is used for pyrolytic carbonization, the PL emission of carbonized fumed silica under UV excitation is composed of two bands, one in the near UV and another in the visible region. It was suggested that the two bands correspond to two different kind of light-emitting centers: type 1 - carbon clusters chemically bonded to the surface and having molecular-like structure similar to that of subnanometer flakes of graphene oxide; type 2-carbon clusters of larger size with less chemical bonding to silica surface. In the case of phenylsilica, we also observe two characteristic PL bands, depending on the processing temperature: near $\mathrm{UV}$ in the sample after annealing $500{ }^{\circ} \mathrm{C}$ and a wider band in the visible range after annealing at a higher temperature (Fig. 5). It is obvious that as the temperature of annealing increases, the size of pyrolytic carbon precipitates on the silica surface grows, starting from molecular-like disordered clusters containing few carbon atoms and still having covalent bonds with silica surface, towards amorphous carbon clusters and nanoparticles with tens and hundreds carbon atoms. Growth of carbon precipitates should be accompanied by breaking of covalent bonds with the surface because the silicon oxide is chemically passivated by the carbon in this temperature range. Thus, the PL properties of annealed phenylsilica are well consistent with hypothesis proposed in Ref. 7.

For further testing of the hypothesis on the nature of two PL bands, we have prepared two series of carbonized materials on the base of fumed silica with a specific surface area of $295 \mathrm{~m}^{2} / \mathrm{g}$. The first series, propoxysilica, has been fabricated by the treatment of fumed silica in the vapor of propanol at temperature $200^{\circ} \mathrm{C}$ that resulted in "grafting" of propoxy groups to the silica surface through $\mathrm{Si}-\mathrm{O}-\mathrm{C}$ bridges. Surface concentration of carbon in this material is several times less than in phenylsilica. At the same time, the number of 


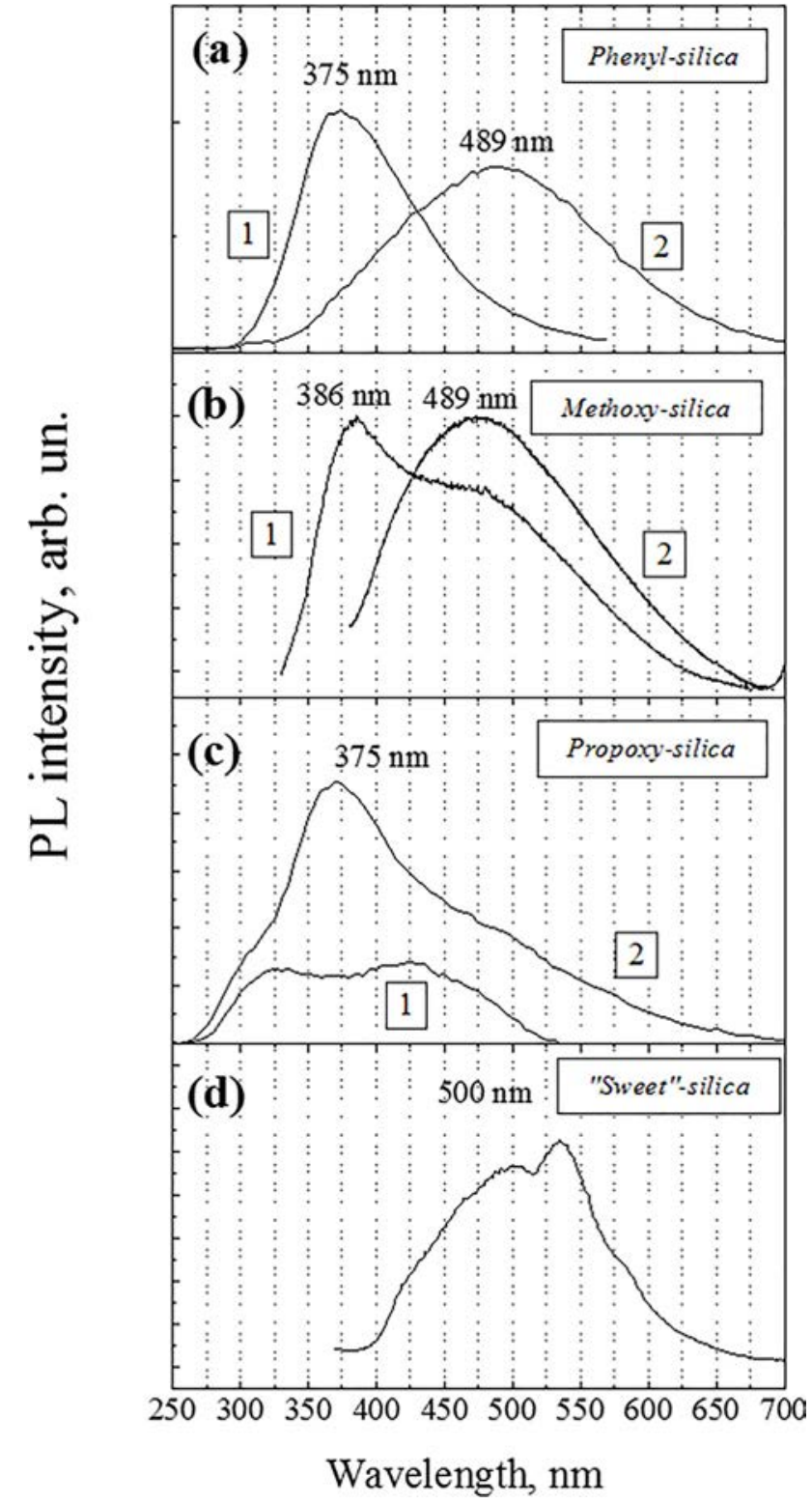

FIG. 9. Comparative illustration of PL spectra of $\mathrm{SiO}_{2}: \mathrm{C}$ powders prepared using different carbon precursor and carbonization treatment: (a) phenylsilica after $500^{\circ} \mathrm{C}$ and $650^{\circ} \mathrm{C}$ annealing; (b) methoxysilica after annealing at $700^{\circ} \mathrm{C}$; (c) propoxysilica before and after annealing at $700^{\circ} \mathrm{C}$; (d) "sweet"silica.

chemical bonds with the surface per carbon atom of the functional group is 1:3 that is significantly higher than in the case of phenylsilica (1:8). Pyrolysis was carried out in vacuum at a temperature of $700^{\circ} \mathrm{C}$ for $30 \mathrm{~min}$.

In the synthesis of the second series, sucrose was used as the carbon precursor: fumed silica powder was infiltrated with a water solution of sucrose and dried, followed by treating in sulfuric acid. As a result of the dehydration, the sucrose molecules break up with the formation of amorphous carbon precipitates. Under such synthesis conditions, no chemical bonds of carbon with the silica surface are expected.

The PL spectra of propoxysilica before and after annealing, as well as "sweet"-silica after chemical carbonization procedure, annealed phenylsilicas, and methoxysilica are summarized in Fig. 9. It can be seen that heat treatment of propoxysilica leads to the appearance of a PL band in the near UV with the maximum intensity at $375 \mathrm{~nm}(4.5 \mathrm{eV})$ [Fig. 9(c)] that is quite similar to that observed in phenylsilica and methoxysilica [Figs. 9(a) and 9(b)]. Photoluminescence of "sweet"-silica is a broad band that covers the entire visible range with the maximum intensity at about $500 \mathrm{~nm}(2.5 \mathrm{eV})$. It is worth noting that broad band PL emission with intensity maximum in the range of $450-500 \mathrm{~nm}$ is quite typical for carbon nanodots prepared by different methods. ${ }^{14}$ Nevertheless light emission of carbon-based nanodots in near UV regions was also reported and usually attributed to oxygen-rich carbon dots in the form of graphene oxide nanoparticles. ${ }^{38}$

\section{B. Structural/energy model}

Figure 10 illustrates a structural/energy model of lightemitting centers, which are formed by the pyrolytic decomposition of hydrocarbon groups and precipitation of carbon on the surface of fumed silica. At low carbon concentration and at a relatively low temperature, small carbon clusters are formed with the presumably significant contribution of covalent bonds with $\mathrm{SiO}_{2}$ surface through C-O and/or C-Si bonds. The near UV emission band (370-380 nm) could be associated with such centers. Fixed spectral position of the maximum and high sensitivity to photo-induced bleaching effects may indicate a molecule-like structure of the centers. C-O and C-Si bridging bonds with the silica surface play likely a key role in the radiative recombination process. With an increase in the carbon concentration and/or pyrolysis temperature, the average size of the carbon clusters should increase, and the bonds with the surface break off, which should result in the decrease of the transition energy and the radiation efficiency. It is obvious that the energy distributions of the radiating centers of type 1 and type 2 overlap in the blue region of the spectrum, which makes possible an energy exchange. Visible PL band exhibits redshift with increasing of the temperature from $600^{\circ} \mathrm{C}$ to $650^{\circ} \mathrm{C}$ (Figs. 5 and 7) that can be attributed in part to a reduction of the concentration of the centers of type 1 (fading of blue region) as well as to an increase in the size of the carbon precipitates (Fig. 10).

\section{Application}

From Fig. S4, one can see that the emission of the $\mathrm{SiO}_{2}: \mathrm{C}$ powder under UV excitation looks as white light. Figure $\mathrm{S} 7$ shows a comparison of the spectral distribution of light emission in the visible range of the black body at $6000 \mathrm{~K}$, and PL of phenylsilica annealed at $600^{\circ} \mathrm{C}$

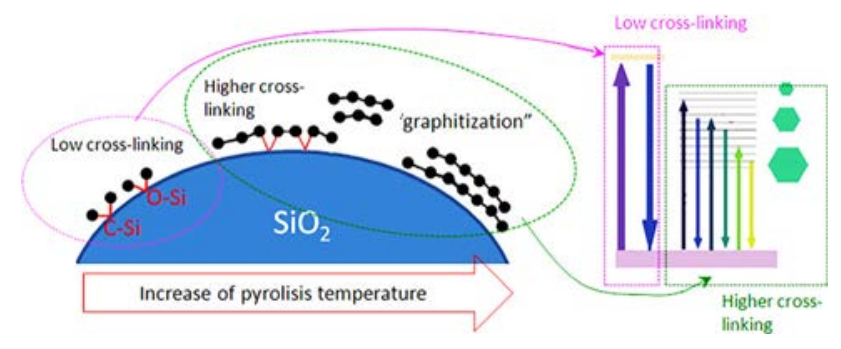

FIG. 10. Suggested structure/energy scheme of carbonized silica surface and its evolution under thermal treatment. 
(excitation $355 \mathrm{~nm}$ ) and methoxysilica (excitation $360 \mathrm{~nm}$ ). Emission of black-body at $6000 \mathrm{~K}$ can be considered as a rough simulation of solar radiation, i.e., natural day-lighting. One can see that the spectral distribution of PL is almost identical to that of black body emission in visible range. Furthermore, spectral properties of the emission (in terms of RGB concept-correlated color temperature) can be easily tuned by the variation of synthesis procedure. Such light emission properties of an environment-friendly single component phosphor make it a very attractive candidate for artificial white light sources like white LEDs with near-UV excitation or compact fluorescent lamps.

\section{CONCLUSION}

In this work, we have detailed the photoluminescent properties of carbonized fumed silica nanopowders. In particular, we have followed the evolution of PL properties associated with the carbonization of fumed silica in a broad temperature range. We have used different surface hydrocarbon precursors, with a gradual transition from organic molecular-like groups to inorganic amorphous carbon precipitates. We have shown that, independent of the carbon precursor used for pyrolytic carbonization, two types of PL bands in the near UV and visible regions can be observed with their relative contribution depending on sample preparation. Based on the analysis of emission/excitation of these two bands, as well as on correlations with the synthesis conditions, a structural-energy model of the light-emitting centers has been proposed. According to this model, the light-emitting centers are associated with nanoscale carbon precipitates. It is assumed that the spectral region of radiation is likely related to the presence or absence of chemical bonds between the carbon emitters and silica surface, as well as to the size of carbon emitters: chemical bonding to surface stimulates near UV emission band while an increase in the size of carbon clusters and weakening of the bonding to the surface decrease PL intensity accompanied by red shift of emission spectrum. Such a mechanism of formation of lightemitting centers makes it possible to control the spectral properties of broadband luminescence in the ultra-wide range and further optimization of emission efficiency and stability. We have clearly highlighted by (S)TEM-EELS analyses the presence of nanoscale carbon precipitates not evenly distributed at the surface of the silica nanoparticles. After thermal treatment at $600^{\circ} \mathrm{C}$, the structure of carbon within these precipitates is mostly amorphous, even if they possess some degree of graphitization and local order. We believe that luminescent carbon species are close in nature to widely reported luminescent $\mathrm{C}$-dots. We suggest that a proper dispersion of carbon nanoemitters in a nanostructured wide band gap (optically transparent) matrix like nanosilicas is one of the methods to avoid aggregation quenching effects, known for C-dots, and increasing of PL efficiency in the solid state. Nevertheless, further specification of the structure of light emitting centers and light absorption/emission mechanisms in nanostructured $\mathrm{SiO}_{2}: \mathrm{C}$ is necessary to verify this hypothesis.

\section{SUPPLEMENTARY MATERIAL}

See supplementary material for several figures concerning XPS, FTIR, PL, and emission black body results obtained on these materials.

\section{ACKNOWLEDGMENTS}

The authors thank the Ministry of Education and Science of Ukraine for support (Project No. F2904) and the Ukrainian Science \& Technology Center (Project No. 6362). The XPS and (S)TEM-EELS studies were conducted at the Laboratorio de Microscopias Avanzadas, Instituto de Nanociencia de Aragon, Universidad de Zaragoza, Spain. R.A. gratefully acknowledges the project "Construyendo Europa desde Aragon" 2014-2020 (Grant No. E/26) and the support from the Spanish Ministry of Economy and Competitiveness (MINECO) through Project Grant No. MAT2016-79776-P (AEI/FEDER, UE). Dr. Guillermo Antorrena (INA, Zaragoza) is thanked for the XPS measurements and fruitful discussions.

${ }^{1}$ A. Edgar, "Luminescent materials," in Springer Handbook of Electronic and Photonic Materials, edited by S. Kasap and P. Capper (Springer International Publishing AG, 2017), pp. 997-1012.

${ }^{2} \mathrm{O}$. S. Wolfbeis, "An overview of nanoparticles commonly used in fluorescent bioimaging," Chem. Soc. Rev. 44, 4743-4768 (2015).

${ }^{3}$ H. Shen, H. Wang, X. Chen, J. Zh. Niu, W. Xu, X. M. Li, X.-D. Jiang, Z. $\mathrm{Du}$, and L. S. Li, "Size- and shape-controlled synthesis of CdTe and PbTe nanocrystals using tellurium dioxide as the tellurium precursor," Chem. Mater. 22, 4756-4761 (2010).

${ }^{4}$ See http://ec.europa.eu/environment/waste/rohs_eee/index_en.htm for EU policy on Restriction of Hazardous Substances.

${ }^{5}$ P. Mushonga, M. O. Onani, A. M. Madiehe, and M. Meyer, "Indium phosphide-based semiconductor nanocrystals and their applications," J. Nanomater. 2012, 869284.

${ }^{6}$ A. Vasin, A. Rusavsky, A. Nazarov, V. Lysenko, G. Rudko, Y. Piryatinski, I. Blonsky, J. Salonen, E. Makila, and S. Starik, "Excitation effects and luminescence stability in porous $\mathrm{SiO}_{2}$ : C layers," Phys. Status Solidi A 209, 1015-1021 (2012).

${ }^{7}$ A. V. Vasin, M. Adlung, V. A. Tertykh, D. Kysil, S. Gallis, A. N. Nazarov, and V. S. Lysenko, "Broad band (UV-VIS) photoluminescence from carbonized fumed silica: Emission, excitation and kinetic properties," J. Lumin. 190, 141-147 (2017).

${ }^{8}$ Y. Ishii, A. Matsumura, Y. Ishikawa, and S. Kawasaki, "White light emission from mesoporous carbon-silica nanocomposites," Jpn. J. Appl. Phys. 50, $01 \mathrm{AF06}$ (2011).

${ }^{9}$ F. Fabbri, F. Rossi, M. Negri, R. Tatti, L. Aversa, S. Ch. Dhanabalan, R. Verucchi, G. Attolini, and G. Salviati, "Carbon doped $\mathrm{SiO}_{\mathrm{x}}$ nanowire with a large yield of white emission," Nanotechnology 25, 185704 (2014).

${ }^{10}$ N. Tabassum, V. Nikas, B. Ford, M. Huang, A. E. Kaloyeros, and S. Gallis, "Time-resolved analysis of the white photoluminescence from chemically synthesized SiCxOy thin films and nanowires," Appl. Phys. Let. 109, 043104 (2016).

${ }^{11}$ Q. Wang, W. Zhang, M. Zhong, J. Ma, Z. Wu, and G. Wang, "Synthesis and photoluminescence of amorphous silicon oxycarbide nanowires," Chin. J. Chem. Phys. 28, 184-190 (2015).

${ }^{12}$ G. Mera, I. Menapace, S. Widgeon, S. Sen, and R. Riedel, "Photoluminescence of as-synthesized and heat-treated phenyl-containing polysilylcarbodiimides: Role of crosslinking and free carbon formation in polymer-derived ceramics," Appl. Organomet. Chem. 27, 630-638 (2013).

${ }^{13}$ P. Roy, P.-C.Chen, A. P. Periasamy, Y.-N. Chen, and H.-T. Chang, "Photoluminescent carbon nanodots: Synthesis, physicochemical properties and analytical applications," Mater. Today 18, 447-458 (2015).

${ }^{14}$ S. Zhu, Y. Song, X. Zhao, J. Shao, J. Zhang, and B. Yang, "The photoluminescence mechanism in carbondots (graphene quantum dots, carbon nanodots, and polymer dots): Current state and future perspective," Nano Res. 8, 355-381 (2015).

${ }^{15}$ L. Lajaunie, C. Pardanaud, C. Martin, P. Puech, C. Hu, M. J. Biggs, and R. Arenal, "Advanced spectroscopic analyses on a: CH materials: Revisiting 
the EELS characterization and its coupling with multi-wavelength Raman spectroscopy," Carbon 112, 149-161 (2017).

${ }^{16}$ K. Gross, J. P. Barragán, S. Sangiao, J. M. De Teresa, L. Lajaunie, R. Arenal, and P. Prieto, "Electrical conductivity of oxidized-graphenic nanoplatelets obtained from bamboo: Effect of the oxygen content," Nanotechnology 27, 365708 (2016).

${ }^{17}$ M. L. Miller and R. W. Linton, "X-ray photoelectron spectroscopy of thermally treated silica $\left(\mathrm{SiO}_{2}\right)$ surfaces," Anal. Chem. 57, 2314-2319 (1985).

${ }^{18}$ G. D. Sorarú, G. D'Andrea, and A. Glisenti, "XPS characterization of gelderived silicon oxycarbide glasses," Mater. Lett. 27, 1-5 (1996).

${ }^{19}$ D. Yang, A. Velamakanni, G. Bozoklu, S. Park, M. Stoller, R. D. Piner, and R. S. Ruoff, "Chemical analysis of graphene oxide films after heat and chemical treatments by X-ray photoelectron and micro-Raman spectroscopy," Carbon 47(1), 145-152 (2009).

${ }^{20}$ R. Rozada, J. I. Paredes, S. Villar-Rodil, A. Martínez-Alonso, and J. M. Tascón, "Towards full repair of defects in reduced graphene oxide films by two-step graphitization," Nano Res. 6(3), 216-233 (2013).

${ }^{21}$ G. S. Chen, C. B. Boothroyd, and C. J. Humphreys, "Novel fabrication method for nanometer-scale silicon dots and wires," Appl. Phys. Lett. 62, 1949-1951 (1993).

${ }^{22}$ L. A. Garvie and P. R. Buseck, "Bonding in silicates: Investigation of the Si L2, 3 edge by parallel electron energy-loss spectroscopy," Am. Miner. 84, 946-964 (1999).

${ }^{23}$ M. C. Ortega-Liebana, J. L. Hueso, R. Arenal, R. Lahoz, G. F. de la Fuente, and J. Santamaría, "Continuous-mode laser ablation at the solidliquid interface of pelletized low-cost materials for the production of luminescent silicon carbide nanocrystals," J. Phys. Chem. C 119, 2158-2165 (2015).

${ }^{24}$ R. F. S. Lenza and W. L. Vaskoncelos, "Preparation of silica by sol-gel method using formamide," Mater. Res. 4, 189-196 (2001).

${ }^{25}$ B. Stuart, Infrared Spectroscopy: Fundamentals and Applications (John Wiley \& Sons, Ltd., 2004).

${ }^{26}$ I. S. Ignatyev b, M. Montejo, F. Partal Ureña, T. Sundius, and J. J. López González, "Vibrational spectra and structure of methoxysilanes and products of their hydrolysis," Vib. Spectrosc. 40, 1-12 (2006).

${ }^{27}$ D. Savchenko, V. Vorliček, E. Kalabukhova, A. Sitnikov, A. Vasin, D. Kysil, S. Sevostianov, V. Tertykh, and A. Nazarov, "Infrared, raman and magnetic resonance spectroscopic study of $\mathrm{SiO}_{2}: \mathrm{C}$ nanopowders," Nanoscale Res. Lett. 12, 292 (2017).
${ }^{28}$ L. Spallino, L. Vaccaro, L. Sciortino, S. Agnello, G. Buscarino, M. Cannas, and F. M. Gelardi, "Visible-ultraviolet vibronic emission of silica nanoparticles," Phys. Chem. Chem. Phys. 16, 22028-22034 (2014).

${ }^{29}$ A. Anjiki and T. Uchino, "Visible photoluminescence from photoinduced molecular species in nanometer-sized oxides: Crystalline $\mathrm{Al}_{2} \mathrm{O}_{3}$ and amorphous $\mathrm{SiO}_{2}$ nanoparticles," J. Phys. Chem. C 116, 15747-15755 (2012).

${ }^{30}$ A. Aboshi, N. Kurumoto, T. Yamada, and T. Uchino, "Influence of thermal treatments on the photoluminescence characteristics of nanometersized amorphous silica particles," J. Phys. Chem. C 111, 8483-8488 (2007).

${ }^{31}$ C. M. Carbonaro, F. Clemente, R. Corpino, P. C. Ricci, and A. Anedda, "Ultraviolet photoluminescence of silanol species in mesoporous silica," J. Phys. Chem. B 109, 14441-14444 (2005).

${ }^{32}$ A. F. Fehervary, L. C. Kagumba, S. Hadjikyriacou et al., "Photoluminescence and excimer emission of functional groups in lightemitting polymers," J. Appl. Polym. Sci. 87, 1634-1645 (2003).

${ }^{33}$ U. Pernisz, N. Auner, M. Baker, "Photoluminescence of phenyl- and methylsubstituted cyclosiloxanes," in Silicone and Silicone-Midified Materials. ACS Symposium Series, edited by S. Clarson et al. (American Chemical Society, Washington, DC, 2000).

${ }^{34}$ M. Dalla Palma, S. M. Carturan, M. Degerlier, T. Marchi, M. Cinausero, F. Gramegna, and A. Quaranta, "Non-toxic liquid scintillators with high light output based on phenyl-substituted siloxanes," Opt. Mater. 42, 111-117 (2015).

${ }^{35}$ M. D'Amico, F. Messina, M. Cannas, M. Leone, and R. Boscaino, "Homogeneous and inhomogeneous contributions to the luminescence linewidth of point defects in amorphous solids: Quantitative assessment based on time-resolved emission spectroscopy," Phys. Rev. B 78, 014203 (2008).

${ }^{36}$ A. V. Vasin, "Structural and luminescent properties of carbonized silicon oxide thin layers," in Functional Nanomaterials and Devices for Electronics, Sensors and Energy Harvesting, edited by A. Nazarov, F. Balestra, V. Kilchytska, and D. Flandre (Springer, 2014), pp. 297-322.

${ }^{37} \mathrm{~L}$. Skuja, "Optically active oxygen-deficiency-related centers in amorphous silicon dioxide," J. Non-Cryst. Solids 239, 16-32 (1998).

${ }^{38}$ G. Xin, Y. Meng, Y. Ma, D. Ho, N. Kim, S. M. Cho, and H. Chae, "Tunable photoluminescence of graphene oxide from near-ultraviolet to blue," Mater. Lett. 74, 71-73 (2012). 